DOI: $10.1515 /$ rpp-2015-0049

$\mathrm{PhD}$ in Interdisciplinary Education, Assistant Professor, SHELBEE R. NGUYENVOGES

Kennesaw State University, USA

Address: 430 Bartow Ave, Kennesaw, Georgia, 30144, USA

E-mail: snguye18@kennesaw.edu

\title{
STORIES OF TRANSITION FROM G. I. JOE, G. I. JANE \& THEIR CLASSMATES: USING CRITICAL INCIDENT NARRATIVES TO PROMOTE SOCIAL INTEGRATION IN THE US FIRST-YEAR EXPERIENCE
}

\begin{abstract}
The purpose of this case study research aims to bridge gaps in the current research by exploring how both veteran and nonveteran adult and higher education (AHE) learners make sense of their educational journey and identity, in and out of the classroom, during their first-year experience (FYE) course at a community college (CC) in the Southwest region. Combining critical incident technique (CIT) and narrative inquiry, the researcher is able to investigate veteran and nonveteran AHE learners' personal critical incident narrative testimonies to make sense of individual identity and values. Relevant literature on the topic of FYE's and transition for veteran and nonveteran learners underscore potentially problematic issues in the current scholarship. The theoretical framework from which this research was undertaken, methodology, findings and discussion reveal how nonveteran and veteran AHE learners identify a 'third side' or common ground in 1) the fight to pursue AHE, 2) the negotiation of new roles and 3) the influence of family on identity. To conclude, implications for future research and conclusions to advance understandings about veteran AHE learners have been offered. Ultimately, participant responses reveal common or 'third sides,' and how these 'third side' spaces contribute towards a collaborative learning environment in an FYE. General experiences of transition into the higher education setting for veteran and nonveteran learners are also shared in the findings.
\end{abstract}

Key words: first-year experience, veteran, nonveteran, adult and higher education, transition, critical incident technique, narrative, identity, critical reflection.

\section{INTRODUCTION}

The recent Post-9/11 G.I. Bill, a legislative effort to increase educational benefits for veterans, stands as the largest increase in federal based education funding since the 1940's (Griffin \& Gilbert, 2012). As such, recent scholarship in adult and higher education (AHE) has placed emphasis on veteran learners and their experiences as first-year students or students in transition (Ackerman, DiRamio \& Garza Mitchell, 2009). While veteran learners are ever-more present on US campuses, veteran students report feeling slightly less supported in the academic settings than nonveteran/civilian students despite specific institutional interventions and initiatives (American Council on Education (ACE), 2011). For this research, veteran learners refer to those enrolled in AHE who have exited the armed services and those who still have military ties, whereas nonveteran students refer to AHE learners who do not have first-hand military experience.

Unfortunately, much of the research concerned with veteran students' transition primarily summarizes efforts that do not work, and do not place emphasis on classroom 
specific initiatives, which have promoted veteran AHE learner success (Bialkowski, 2012). Additionally, B. Bialkowski (2012) offers some specific suggestions and next steps for AHE scholars, practitioners, faculty, and staff whose aims are to enrich the educational experience of veteran students. Some of these next steps include enhancing understanding of veteran students, and the issues that might serve as obstacles to their educational experience (American Council of Education (ACE), 2010). Further, institutions need to develop knowledge and insight across AHE with regard to military culture, the nuances of the GI Bill, veteran experiences in and out of the classroom, and stereotypes that they might encounter from nonveteran populations within the academic community (ACE, 2010).

\section{THE AIM OF THE STUDY}

The purpose of this case study research aims to bridge gaps in the current research by exploring how both veteran and nonveteran AHE learners make sense of their educational journey and identity, in and out of the classroom, during their first-year experience course at a community college (CC) in the Southwest region. Combining critical incident technique (CIT) and narrative inquiry, we are able to investigate veteran and nonveteran AHE learners' personal critical incident narrative testimonies to identify common, or "third spaces", and how these communal, or third spaces, create a collaborative learning environment in an FYE. General experiences of transition into the higher education setting for veteran and nonveteran learners are also shared in the findings. The following sections detail relevant literature on the topic, the theoretical framework from which this research was undertaken, methodology, findings and discussion which reveal how nonveteran and veteran students identify 'third space,' or common ground, in the classroom through critical incident narratives. To conclude, implications for future research and conclusions to advance understandings about veteran AHE learners have been offered.

\section{THEORETICAL FRAMEWORK AND RESEARCH METHODS}

This research is framed within adult education theory and practice. In order to narrow the scope of study and offer specificity to meaningful stories of experience, learners were asked to identify one or two specific critical incidents (Flanagan, 1954) that shaped who they are today. First introduced by J. Flanagan and popularized in higher education, communication and management research, the two-part critical incident technique (CIT) makes use of descriptive stories of experience and then breaks these down within the broader, cultural and social context (Gray, 2007). According to J. Flanagan (1954) "an incident is critical if it makes a 'significant' contribution, either positively or negatively to the general aim of an activity" (Flagan, 1954). D. Simmons and J. Trenor (2010) use CIT to investigate how firstgeneration college students reflect on critical incidences when choosing their academic majors and how those specific social familial interactions shape these choices. Gray (2007) posits that "critical incidents, then, can be highly personal in nature and can help to trigger deep and sometimes discomforting, introspection, even becoming developmental turning points" (Gray, 2007). While critical incidents may not necessarily be momentous or dramatic, and can often be mundane or part of a typical routine, the CIT offers flexibility in identifying motivations and attributions from the individual perspective. H. Hughes, K. Williamson and A. Lloyd (2007) remark that CIT is "capable of yielding rich, contextualized data that reflect real-life experiences" which is ideal for diverse learners (Highes, Williamson, Lloyd, 2007).

The use of narrative, reflection and critical incidents as process is no new idea, but the use of narrative and CIT to foster community in the FYE classroom for veteran and nonveteran students is a relatively new and unexplored phenomenon. The intersection of 
experience, reflection and learning is central to adult education theory practice, and also to engagement in the learning context. J. Lave and W. Wenger (1991) illustrate this by noting that learning is most meaningful when it happens collaboratively within the context of the community. Not much scholarship exists on how community can be collaboratively built through narrative for veterans and nonveterans within the First-Year Experience, and how this might translate to more engagement in the college experience (Ackerman et al., 2009).

Making use of the "third side" is what W. Ury (2000) simply describes as identifying common ground rather than focusing on how two sides oppose one another. Students in the community college setting often share a plethora of "third side" space by coming from the same city, sharing similar status as a first-generation college student (the first to attend college in their family), and/or sharing similar cultural or multicultural experiences from the home city. K. Jones (2013) asserts that connecting these previous experiences to meaning made about present experiences, for these learners in the community college classroom, is a powerful way to help higher education professionals understand the nuances of the transition into higher education for veteran AHE learners. Additionally, the discipline of adult and higher education has long urged these same professionals to use stories of experience, or personal narratives, as a powerful tool and resource for meaningful, transformative learning (Mezirow, 1990). Central in this case study are ways in which veteran and nonveteran students build social relationships, and foster "third side" space, via narrative testimonies.

The first-year experience (FYE), first-year seminar, and transfer-student seminar individually and synonymously aim to provide academic, social and course content support to promote student success in a time of transition when students are beginning, or restarting their academic journey (Bliss et al., 2012). C. Bliss et al. (2012) indicate that nearly 90 percent of all four-year universities/colleges across the United States have some version of a FYE, which aims to build relationships within the campus community and encourage progression/retention. E. Pascarella and P. Terenzini (2005) suggest that one of the most notable and well-documented effects of participation in a first-year experience (FYE) is retention and progression between the first and second years in AHE. M. Torenbeek, E. Jansen, and W. Hofman (2011) discuss how critical the first few weeks of adjustment and transition into institutions of AHE learning are for academic and social integration. This is especially true for individuals who transition from combat to the classroom as a first-year student. This research primarily concerns itself with how social integration occurs for veteran and nonveteran learners early in the transition experience when they share critical incident narratives.

Problematisation of Veterans and Nonveterans. There are two specific issues identified in scholarship concerned with veteran AHE learners' transition that potentially problematize the research and limit new understandings about social adjustment. The first issue being that institutions of higher learning market to veteran learners by self-identifying as "military friendly" when there is not consensus on exactly what that means. Some intuitions, and their veteran specific curricular and/or co-curricular initiatives, earn credit as being "veteran friendly" or "military friendly," however, there is not wide agreement about how an institution is granted this status and what sort of approaches they use to build community, foster third space and encourage social adjustment (Griffin \& Gilbert, 2012). Some institutions may do this as a marketing tool; while others are motivated by concerns for existing veteran specific issues currently being experienced at the institution (Ackerman et al., 2009). Other institutions of AHE make efforts to create a repository of vet resources, FAQ 
guides, spaces for collaborative dialogue with other veterans, or offer online flexibility (Kim \& Cole, 2013). Again, there is not much scholarship that details how veteran and nonveteran students build social relationships within these outlets.

The second issue can be found in how current research frames/operationalizes veterans and nonveterans within scholarship, and what suggestions the same research offers to promote building relationships on campus for these AHE learners. What is problematic is the notion that these groups are treated as opposite or polarized groups (Kim \& Cole, 2013). Often times the scholarship will evaluate and assess veteran students responses versus nonveteran students' responses to identify how these groups are different, or divergent when it comes to learning style, learning preferences and relationships with members of the academic community (ACE, 2009). Much of the scholarship, like D. Raybeck (2010), indicates that veteran students have difficulty relating, finding common ground, or identifying "third side" with nonveteran students. Thus, much of the literature directs members of the academic community to create spaces and opportunities so that military students can find and connect with each other as a remedy to alienation, and ultimately, withdrawal (Ackerman et al., 2009). V. Tinto (1993) cautions that these "segregating" strategies can offer initial comfort in a chaotic time of transition, but ultimately "fail to help the student veteran fully transition and integrate with the broader 'civilian' campus community" (Tinto, 1993). Again, this challenges FYE instructors with the task of building authentic spaces to find common ground, shared experiences, and thus build social relationships and across and within veteran and nonveteran student groups to diminish likelihood of drop-out (ASHE, 2011).

The design of this case study was exploratory in nature to capture how both veteran and nonveteran use critical incident narratives as a reflective tool to encourage social integration and collaborative learning. C. Clark and M. Rossiter (2008) explain how important narrative can be as a method to foster understanding, and also "conceptualize learning as a narrative process" (Clark \& Rossiter, 2008). This is particularly important for this case study, which includes multicultural, first-generation veteran and nonveteran students at a Hispanic serving community college. Nearly $65 \%$ of the total student population is Hispanic learners, with a mean age of 24 years of age. $55 \%$ of the minority student population report being the first in their family to attend college, or first-generation students.

Participants. J. Corbin and A. Strauss (2008) suggest that qualitative methodologies "allow researchers to get at the inner experience of participants, to determine how meanings are formed through and in culture, and to discover rather than test variables" (Corbin, Strauss, 2008). 84 students across four sections of the FYE self-identify as multicultural (1), Hispanic (43), Mexican (8), Latino(a) (11), Dominican (2), African-American (6), Black (1), Caucasian (4), White (6), Ecuadorian (1), and Russian-American (1). There were 40 female and 44 male participants with a mean age of 28. 24 participants identified as "veterans," - "those who have exited the armed services and those who still have military ties" (ASHE, 2011). 53 of the participants identified themselves as students who are the first to attend college in their family. Students were debriefed as to the purposes of the study and given an opportunity to withdrawal their course material and testimonies for inclusion if they wished; none did so.

Procedure. CIT involves a two-step process that involves a rich descriptive event, which connects to the aims of a specific activity. The second step includes the broader, cultural and social context that contributes to meaning made about that incident. The aim of the specific class activity was general in nature and tasked students to think about 1) Who 
am I? and 2) What do I value? Learners were tasked to develop their descriptive narrative outlining their one or two critical incidences and incorporate any meaningful anecdotes, examples and individuals that might have contributed to identity production or understanding identity. They completed this on their own over the first three weeks of the course. This activity was part of a larger module on aligning intrinsic motivations to shortterm and long-term personal, academic and professional goals.

By asking learners to identify one or two critical incidents that significantly contributed to their personal narrative about who they are and what they value, students are able to share resources and insights of highest value. The second part of the CIT process was employed within a large focus group setting of eight-ten participants and asked students to synthesize their thoughts in a five to seven minute narrative testimony speech. These were done over the course of three days for each of the four sections of the course. 10-20 minutes of "unpacking" and discussion took place after all participants' critical incident narrative testimonies were shared. The unpacking session included three openended questions that were posed to each of the focus groups publically (aloud orally) and privately (on a handout) these questions asked:

1) What efforts have you made to connect to your campus?

2) What has been meaningful in your first weeks at the CC? (This can be ANYTHING inside or outside of the classroom around campus).

3) What other comments would be helpful to understanding your thoughts and feelings regarding your FYE and transition into college?

Analysis. C. Reissman (2008) suggests narrative analysis is preferable when analyzing "individuals in stories of experience" (Reissman, 2008). However, several models or typologies of narrative analysis exist, all of which overlap in some way. Using "thematic analysis" places importance on the content itself focusing on the messages and "what is said, more than 'how' it is said" so that the most important patterns and trends can be identified (Reissman, 2008). This grounded approach is ideal for individual cases and testimonies that offer illustrative value to a particular phenomenon or occurrence (Reissman, 2008) like veteran and nonveteran multicultural first-generation students critical incident narratives in the FYE.

\section{RESULTS}

Third side: the fight. Participants in this case study research revealed personal stories and experiences that have shaped them and influenced their identity. In developing a critical incident narrative through loose, open-ended questions like "who am I and what do I value," participants uncovered the moments in their lives that most directly influence where they are today as a new college student. There is not much to deny the fact that a traditional aged Caucasian learner between the ages of 18-23 may have much different lived experiences than a non-traditional aged 38-year-old Hispanic veteran when entering/reentering into AHE. But, every student regardless of age and disposition comes to the classroom for a reason and battles against unique challenges before, and during their journey in higher education. This was the case for many students within this case study.

Nearly $80 \%$ of the participants in this case study research identified "struggle", "obstacles", "challenges", "trials" that were barriers which complicated or made it difficult to stay in or go back to college. For Joe, a Dominican male participant it was personal doubt and an inability "to take myself seriously, and not worry about failure," and for Julie, a Hispanic veteran female student, it was actual battle. She commented that her transition from "JROTC (Junior Reserve Officer Training Corps) into active duty" was filled with 
traumatic memories, "but enlisting after high school is what people do if they want college where I am from." Like W. Astin (1993), and other research concerned with veteran students' transition, scholars indicate that making connections with other veterans could be crucial for initial success and persistence when starting college. However, this research could argue that making connections in personally relevant ways need not discriminate to members of the in-group, or only veteran learners. No doubt, obstacles encountered by veteran and nonveteran learners are individually powerful critical incidents that make the goal of higher education a daunting, but worthwhile endeavor.

Additionally, some participants took issue with specific experiences, prior to entry into college, and identified that negative experience as a reason for wanting to pursue college. Charles, a Hispanic veteran stated that "my time deployed made PTSD and lack of options for young veterans real, they come alive. I haven't been a student since high school so being a psych major scares me, but that's real." Participants share the struggles encountered, both emotional and experiential serve as drivers moving them into the learning environment. Another illustration of this comes from a Caucasian female student, Lee. Lee shared her struggle with prescription pills in high schools and noted:

"I was "a smart girl," that's what they would say about me, it was

a huge shock to everyone that I was doing so bad and just not caring all

together. I realize now that those bad choices and that old life made me

want this one (higher education/sobriety) even more and I want to help

kids who are going thru some of the same stuff".

Testimonies from Lee and Charles, a traditional nonveteran female learner and nontraditional veteran learner respectively, indicated not only that their experiences challenged them, but they also expressed altruistic intentions to help others who may be effected by some of those same issues. Both of these learners took notice of their own struggle and negative experiences and use these as powerful pieces of intrinsic motivation to connect to a specific major (in Charles' case) or a specific occupation (in Lee's case). This becomes important within the FYE as learners are challenged to think about how their own previous experiences connect to their future, and what new roles and responsibilities they might take on in pursuit of that future.

Third side: new roles. In thinking back on important critical incidents, participants were confronted with making sense of their past and how it connects to identity and what they value. D. DiRamio and K. Jarvis, in ASHE (2011), discuss the importance for veterans to think about how their roles and assumptions may have changed as a result of their military experience, but again, this is true for all students entering/reentering higher education. Participants recognize that the act of reflecting on identity and critical incident narratives is not a natural or familiar process, likely because K-12 education and the armed forces underscore transactional methods, which could discourage this kind of introspection and interaction. One student anonymously and privately reflected that "making it a personal experience instead of a professional classroom" was meaningful for him in the first few weeks at the CC. Learners here acknowledged that the task of reflecting on critical incidences, in and of itself, is difficult and challenges them to think about what the role of student means from their own individual perspective. Ultimately, it challenges the learner to pioneer their own path, rather than simply following "orders" or "directions" from faculty or superiors in the words of several veteran and nonveteran participants. Additionally, developing and sharing critical incident narratives privately and aloud to the focus group is challenging in that learners exposed some of their most intimate thoughts and feelings. 
Through the critical incident narrative, learners authentically created bonding space "to open up and get others to open up" according to one female participant self-identifying as Mexican. This authentic space gave participants opportunities to bond over the challenge of speaking on intimate/personal experiences while simultaneously reconciling goals for the future as a new college student. A participant identifying as a female Ecuadorian shared that "getting an opportunity to remember why I loved that experience and how it changed me was really meaningful in my first weeks of college, it reminded me why I am here, and what I came to do".

Participants collectively shared in the experience of exposing their inner thoughts about experiences and identity, which bonded the learners in unique and individual ways. Several participants remarked in their private feedback that "learning about each person and their experiences" was meaningful to their first few weeks at the CC. Further, participants like Matthew, a Hispanic veteran, remarked on how important and meaningful it was for his classmates "to get an idea of who I am, as a vet, student, dad, son, and brother". Ultimately, participants appeared to appreciate the opportunity to tell their story and discuss the ways that their current or previous roles in life were changed and challenged by being a new student in the community college context. Another learner identifying as a male Russian American veteran noted that "sharing my trials has helped me to understand where I come from and where I am going".

Both veteran and nonveteran learners within the case intimated that sharing within classroom space can be "intimidating," "scary" and even "overwhelming" according to a nonveteran student identifying as African American. While learners found common ground or "third side" space in dialogue about the multiple roles they play, each learner is uniquely challenged to be his/her own agent in decisions about their own future. Participants here expressed some discomfort in being "the captain to this mission," according to a Hispanic male veteran, or anxiety about self-regulating and self-directing his/her own choices and decisions. Students dialogue about roles they play, played or will be challenged to play and express that negotiating these with others is comforting and meaningful in their FYE and first weeks of transition at the CC.

Third side: family. Communally, students reflect on "Who am I?" and "What do I value?" by sharing how specific experiences prior to deployment or entry into higher education, and the individuals involved, influence or shape identity. Many veteran and nonveteran learners identified common ground in how their relationships with family members, and close friends shape their identity and values. Lee aptly stated:

"sometimes life is about finding people who support you and recognizing those who do the opposite, I am who I am today, and where I am today, right now because of these people".

Another Hispanic female, Marie, shared memories of her "abuela" and how their "spiritual connection" in times of trauma had always been a defining characteristic of who she is and what she values. She went on to speak about how her "faith and trust in the human spirit" could never have been fully realized had she not had this relationship. Two different Hispanic veteran males also indicated that messages of "discipline" and "service" were instilled at a young age. For one of these individuals, Caleb, these messages came through for the first time when he "was busted for stealing a pack of candy cigarettes at the age of six." Other illustrations of critical incidents showcase duty and responsibility to the family across both veteran and nonveteran learners.

Tyler, self-identified as a Black combat veteran, speaks on perceptions of military duty and messages received about service. He shared: 
"I hate when I get thanked for my service, it shouldn't be celebrated. I'm honoring a tradition in my family and this is what is important to us. When people say that kinda" stuff over and over, it's like they don't get it or me, like I am trying to save and protect our world, but its smaller than that, I don't know...".

Both veteran and nonveteran AHE learners reconcile messages from family networks in very powerful ways. Nearly all of the 84 critical incident narratives, with the exception of 4 , credited someone within the family or friend network as key players shaping and influencing whom each of them identified as and the values that sustain those identities.

Several stories of "courage," "perseverance," "commitment" and "service" from the family echoed across veteran and nonveteran critical incident narratives. Students indicate, in their narratives, that the people in their life play a profound role in shaping who they are and what they value. In many cases, recalling conversations and critical incidents involving these individuals was a powerful way to visit short term and long-term goals at the start of an FYE.

\section{CONCLUSIONS}

Ackerman et al. (2009) suggest that institutions of AHE must create explicit avenues for supporting veteran learners as they negotiate their new roles as students, but do not include much commentary or inclusion of nonveteran students within these initiatives. Y. Kim and J. Cole (2011) found that veteran students often report that they do not feel supported on campus to succeed. While much of the scholarship underscores what the current state of affairs looks like from an institutional perspective, not much attention has been paid to inclusive classroom strategies that bring veteran and nonveteran learners together. "The ability to integrate socially and succeed academically is particularly important" and as, such this research makes use of the "third side" to encourage social integration for veteran and nonveteran learners in the FYE. The exploratory nature of this study allowed both veteran and nonveteran students to reflect on their personal lives to identify one or two critical incidences that contribute to their personal narrative (who they are, what they value), and what sustains each of them as veteran, or nonveteran CC students in a FYE. Findings across the case study revealed specific ways that veteran and nonveteran learners create third-side dialogue and reflect on what is meaningful in the first few weeks of transition.

Many scholars like D. DiRamio and K. Jarvis, in ASHE (2011), who are concerned with veterans' transition experiences, stress Brenner's (2008) research which indicates that many veterans cannot identify with general society because "out in society, there is a disconnection" (ASHE, 2011). Dialogue and subsequent unpacking of identity, values, meaning made and general experience of transition into AHE in the first 3-4 weeks of transition at the $\mathrm{CC}$ reveal that veteran and nonveteran students are more than capable of creating identifications with one another. Critical incident narratives became a powerful way for veteran and nonveteran students to connect in authentic and experiential ways as they reflect on identity and values within the classroom. Nonveteran and veteran students had a variety of stories to share about complications, difficulties, troubles as well as triumphs. As new students to a new learning environment, both veteran and nonveteran learners were able to find common ground in life before college, the identification of new roles and in drawing influences from the family networks.

FYE: a space to reconcile experiences. This research responds, in part, to recent scholarship, like Y. Kim and J. Cole (2013) that identifies the need to understand what the experiences of veteran AHE learners' looks like. Authors suggest, "gauging these students' experiences, college and university leaders can assess how to improve programs and 
services to support student veterans/service members and improve their educational outcomes" (Kim \& Cole, 2013). This case study provides a preview into how Hispanic veteran learners reconcile intrinsic motivation from their past experiences and how they use these past experiences to drive their academic journey. While both multicultural veteran and nonveteran learners each encounter challenges in initially entering/re-entering into AHE, veteran learners in particular are specific in how combat experiences and military life in general, encourage them to follow a particular life path. For students in this case study research, some of these paths included counseling, physical therapy, psychology, and other social support services for combat veterans.

In many ways this activity is supported by previous research, which encourages students to seek out social support and assistance with resources/individuals that they feel bonded or likened to (Schlossberg, 1981; 1984). While this has traditionally manifested in the collection of veteran resources and centralized campus initiatives for veteran learners (Bliss et al., 2012), this research asserts that the classroom, and the FYE can also be this resource. The FYE is an ideal space for students to discuss their changing roles, family influences and what their personal motivations are in pursuing AHE. Specific activities aimed at exploring identity and motivations can be powerful for social integration in the first, overwhelming weeks of a semester. Additionally, creating spaces for veteran and nonveteran students to come together and identify "third side" spaces cannot be undervalued or overlooked.

\section{REFERENCES}

1. ACE. (2010). Veteran Success Jam: Ensuring Success for Returning Veterans. Retrieved 12.08.2015 from: http://www.acenet.edu/Content/NavigationMenu/ProgramsServ ices/MilitaryPrograms/serving/index.htm.

2. ACE. (2011). Accommodating Student Veterans with Traumatic Brain Injury and Post-traumatic Stress Disorder: Tips for Campus Faculty and Staff. Retrieved 11.08.2015 from : http://www.acenet.edu/Content/NavigationMenu/ProgramsServices/MilitaryProgram s/serving/Accommod atingStudentVeterans_06222011.pdf.

3. Ackerman, R., DiRamio, R., \& Mitchell, G. (2009). Transitions: Combat veterans as college students. New Directions for Students Services, No 126, pp. 5-14.

4. ASHE. (2011). Veterans in Higher Education: When Johnny and Jane Come Marching to Campus: ASHE Higher Education Report, Volume 37, No 3, 152 p.

5. Astin, W. (1999). What Matters in College: Four Critical Years Revisited. San Francisco : Jossey-Bass, $512 \mathrm{p}$.

6. Baumgartner, L. (2001). An Update on Transformational Learning Theory. In Merriam, S. B. (Ed.). The New Update on Adult Learning Theory San Francisco, CA : Jossey-Bass, pp. 15-24.

7. Bell, J. (2002). Narrative inquiry: More than just telling stories. TESOL Quarterly, No 36 (2), pp. 207-213.

8. Bialkowski, B. (2012). Called to serve: A handbook on student veterans on higher education. Higher Education, 2012, pp. 18-22.

9. Biggs, S., Torres, S. \& Washington, N. (1998). "Minority student retention: A framework for discussion and decision making". Negro Educational Review, No 49, pp. $71-82$. 
10. Bliss, C., Webb, J. \& Andre, M. (2012). The impact of the University of Utah's LEAP Program on student performance. Journal of General Education, No 61 (1), pp. 39-58.

11. Brenner, L. (2008). A qualitative study of potential suicide risk factors in returning combat veterans. Journal of Mental Health Counseling, No 30(3), pp. 211-225.

12. Clark, C. \& Rossiter, M. (2008). Narrative learning in adulthood. New Directions for Adult and Continuing Education, No 119, pp. 61-70.

13. Corbin, J., \& Strauss, A. (2008). Basics of Qualitative research: Techniques and Procedures for Developing Grounded Theory. Thousand Oaks : Sage, 456 p.

14. Flanagan, J. (1954). The critical incident technique. The Psychological Bulletin, No 51 (4), pp. 327-358.

15. Gray, D. (2007). Facilitating management learning: Developing critical reflection through reflective tools. Management Learning, No 38 (5), pp. 495-516.

16. Griffin, K., Gilbert, C. (2012). Easing the Transition from Combat to Classroom. Preserving America's Investment in Higher Education for Military Veterans Through Institutional Assessment. Center for American Progress. Retrieved 1.08.2015 from : http://www.americanprogress.org/wpcontent/uploads/issues/2012/04/pdf/student_vet erans.pdf.

17. Hoge, C. (2010). Once a Warrior, Always a Warrior: Navigating the Transition from Combat to Home. Guilford : Globe Pequot Press, 328 p.

18. Hughes, H., Williamson, K., Lloyd, A. (2007). Critical Incident Technique. In: Lipu, S. (Ed) Exploring Methods in Information Literacy Research. Wagga Wagga : Centre for Information Studies, pp. 353-385.

19. Jones, K. (2013). Understanding student veterans in transition. The Qualitative Report, No 18 (74), pp. 1-14.

20. Kim, Y., Cole, J. (2013). Student Veterans/Service Members' Engagement in College and University Life and Education. ACE. Retrieved 2.08.2015 from : http://www.acenet.edu/news-room/Pages/Student-Veterans Service Members Engagement.aspx.

21. Lave, J., Wenger, W. (1991). Situated Learning: Legitimate Peripheral Participation. New York, Cambridge University Press, 138 p.

22. Mezirow, J. (1990). How Critical Reflection Triggers Transformative Learning. In : Mezirow, J. (Ed). Fostering Critical Reflection in Adulthood. San Francisco : JosseyBass Publishers, pp. 1-20.

23. Mullet, J., Akerson, N., Turman, A. (2013). Healing the Past Through Story. Adult Learning, 24 (2), pp. 72-78.

24. Nelson Goff, B., Irwin, L., Cox, M., Devine, S., Summers, K., Schmitz, A. (2014). A qualitative study of single-trauma and dual-trauma military couples. Psychological Trauma: Theory, Research, Practice, and Policy, No 6 (3), pp. 216-223.

25. Pascarella, E., Terenzini, P. (2005). How College Affects Students: A Third Decade of Research. San Francisco : Wiley, $842 \mathrm{p}$.

26. Patton, M. (2002). Qualitative Research and Evaluation Methods (3rd ed.). Thousand. Oaks, CA : Sage, 832 p.

27. Radford, A., \& Wun, J. (2009). Issue Tables: A Profile of Military Servicemembers and Veterans in Postsecondary Education in 2007-08 (NCES 2009-182). National Center for Education Statistics, Institute of Education Sciences, U.S. Department of Education. Washington, DC. Retrieved 10.08.2015 from : http://nces.ed.gov/pubs2011/ 2011163.pdf.

28. Raybeck, D. (2010). Clash of cultures: Veterans in academe. In Improving College Education of Veterans, pp. 179-196. Create Space Independent Publishing Platform. 
29. Reissman, C. (2008). Narrative Methods for the Human Sciences. London : Sage, $264 \mathrm{p}$.

30. Simmons, D., Trenor, J. (2010). Use of the critical incident technique for qualitative research in engineering education: An example from a grounded theory study. Proceedings of the 2010 American Society for Engineering Education Annual Conference and Exhibition, Louisville : ASEE, 13 p.

31. Schlossberg, N. (1981). A model for analyzing human adaptation to transition. Counseling Psychologist, No 9, pp. 2-18.

32. Schlossberg, N. (1984). Counseling Adults in Transition: Linking Practice with Theory. New York : Springer, 299 p.

33. Tinto, V. (1993). Leaving College: Rethinking the Causes and Cures of Student Attrition. $2^{\text {nd }}$ ed. Chicago : University of Chicago Press, 296 p.

34. Torenbeek, M., Jansen, E. Hofman, W. (2011). Predicting first-year achievement by pedagogy and skills development in the first weeks at university. Teaching in Higher Education, No 16 (6), pp. 655-688.

35. Ury, W. (2000). The Third Side: Why We Fight and How We Can Stop. Boston : Penguin, $251 \mathrm{p}$. 